\title{
Analysis of Series-Connected IGBTs Protection Method Under Short Circuit II
}

\author{
Mei Guifang, Xu Guancheng, Lv Miao, Lang Xuebin, Dong Xiaoshuai, Yang Xinran
}

Xi'an Xuji Power Electronic Technology Co., Ltd., Xi'an, China

\section{Email address:}

mei_gf@126.com (Mei Guifang),940771079@qq.com (Xu Guancheng), 13630284819@163.com (Lv Miao), langxb359@163.com (Lang Xuebin),1601000695@qq.com (Dong Xiaoshuai),yxr0103@163.com (Yang Xinran)

\section{To cite this article:}

Mei Guifang, Xu Guancheng, Lv Miao, Lang Xuebin, Dong Xiaoshuai, Yang Xinran. Analysis of Series-Connected IGBTs Protection Method Under Short Circuit II. Journal of Electrical and Electronic Engineering. Vol. 4, No. 5, 2016, pp. 139-144.

doi: $10.11648 /$ j.jeee.20160405.18

Received: October 22, 2016; Accepted: November 22, 2016; Published: November 24, 2016

\begin{abstract}
The difference between single and series-connected insulated gate bipolar transistor (IGBTs) during short circuit II (SC II) is analyzed contrastively, and requirements for an improved protection have been advanced to solve the SC II problem of series-connected IGBTs. A new principle of short circuit protection based on the logic of SC II fault processing used by the main control unit was proposed, using an active voltage clamping circuit to balance the dynamic voltage during breakdown, using an $\mathrm{RC}$ circuit to balance the voltage during tail current stage, and a formula to estimate the absorption capacitance and the selection principle of static voltage balancing resistance was proposed. The parameters under the actual test condition was given, the short circuit test system of series-connected IGBTs established, and the experimental verification carried out under the actual conditions. The result shows that under a Vbus of $1400 \mathrm{~V}(2.65 \mathrm{kV}$ maximum peak voltage for each IGBT), the new protection method can provide synchronization of protect operation and voltage balancing during turning-off process, and the unbalance of steady stage voltage is under $5 \%$.
\end{abstract}

Keywords: Series-Connected IGBTs, Short Circuit in Series, SC II, Fault Detection, Voltage-Balancing in Fault

\section{Introduction}

High voltage power transmission technology play an increasingly important role in long-distance transmission, renewable energy and distributed generation fields, while the commutation system is the core component of High Voltage Direct Current (HVDC) system. As the development of semiconductor device technology, the voltage source converter based on high voltage and high power insulated gate bipolar transistor (IGBT) has been widely used in DC power transmission technology. Because the DC voltage level of the flexible HVDC system is higher than that of the single IGBT, it is important to improve the power level of the device by using the series-connected IGBTs modules. [1-2] The press pack IGBT has double side heat dissipation, and the current density is higher under the same voltage level, especially for use in series [3-4]. IGBT series applications need to solve two problems: 1) voltage balancing of series-connected IGBTs in the normal operating state; 2) the problem of short circuit in series in the fault state. The key of voltage-balancing is to ensure the consistency of turning-off delay time and the rising rate of turning-off voltage of the series-connected IGBTs. Since 1990s, there are experts and scholars began to explore the method of dynamic equalization of series-connected IGBTs. The method of voltage-balancing of series-connected IGBTs schemes mainly includes the load side buffer circuit and gate control. Combine the use of gate synchronous control [5] and load side buffer circuit [6], realized voltage-balancing of series-connected IGBTs, but there are relatively few analysis fault characteristics and effective solutions for short circuit II in series-connected IGBTs. [7-9]

From the traditional voltage source converter topology, short circuit model of IGBT is divided into upper and lower bridge short-circuit fault, bridge arm to phase short-circuit fault and bridge arm to ground short circuit [10-11], as shown in Figure 1. The bridge arm short-circuit fault occurred in the turning-off state has just entered into the turning-on state, which called short circuit I, the main reason is the power module failure or driving signal error. Bridge arm to phase short-circuit fault and bridge arm to ground short circuit of the 
load side during turning-on state called short circuit II, the main reason is the load side insulation failure or line connected wrong.

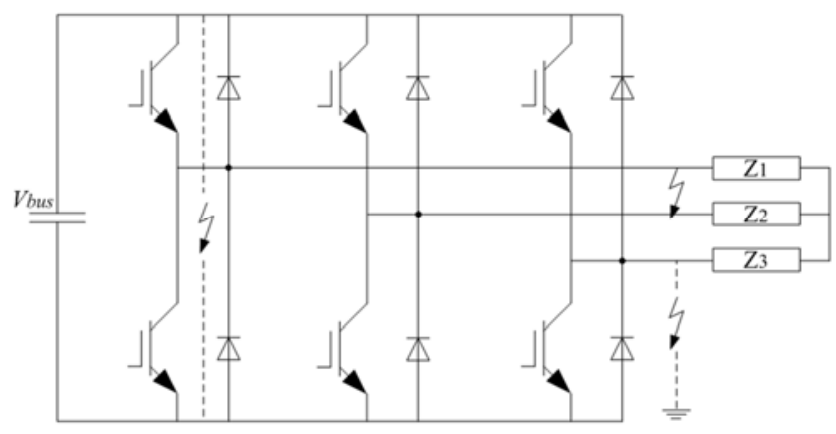

Figure 1. Diagram of IGBT short circuit types.

With the improvement of manufacturing process and drive unit control technology, short-circuit I fault occurred less in the actual engineering application. As the converter load side line is complex and the equipment interface is numerous, short-circuit II fault occurs more easily. Therefore, according to the short circuit II fault of IGBT, this paper analysis the characteristic difference between single and series-connected IGBTs during SC II detailed. And propose the protection logic and voltage-balancing method of series-connected IGBTs when short-circuit II fault, and verified protection case under high voltage and high current condition.

\section{The Characteristic Difference Between Single and Series-Connected IGBTs During SC II}

The change of collector voltage Vce, short-circuit current Ic and gate voltage Vge when short-circuit II fault [12] is shown in Figure 2.

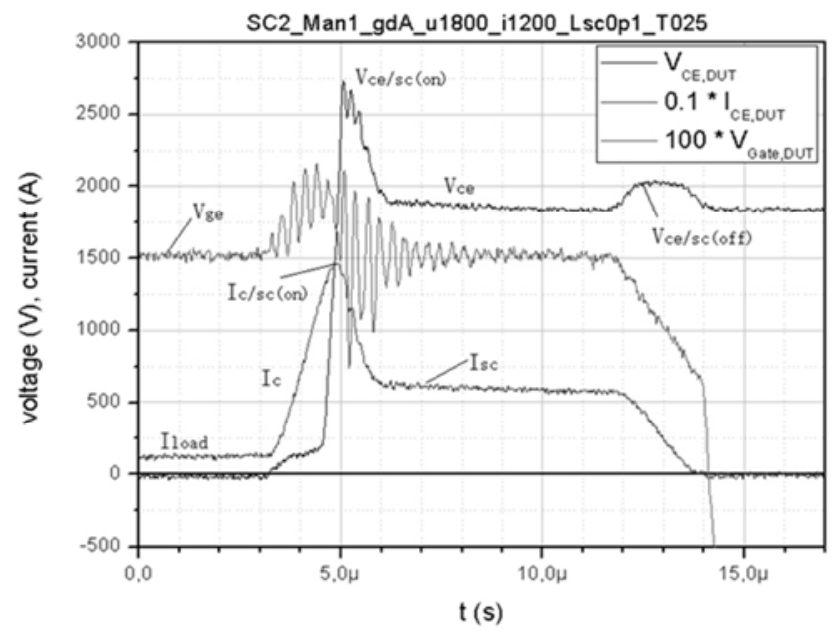

Figure 2. Short circuit II in a single $2.5 \mathrm{kV}$ IGBT module.

When the pulse is open, collector emitter voltage Vce drop to saturation voltage Vcesat; in case of a short circuit, the collector current Ic will increase sharply, the value of di/dt is determined by the DC bus voltage Vbus and short circuit inductance Lsc. With the further increase of Ic, Vcesat increased slightly, when the current reaches to the saturation point Isc/on and Vce rose to the DC bus voltage quickly, short circuit current decreased to a static value Isc, the Vce/sc (on) which is negative $\mathrm{di} / \mathrm{dt}$ generated on a parasitic inductance is:

$$
V_{\text {ce } / \mathrm{sc}(\mathrm{on})}=V_{\mathrm{bus}}+L_{\mathrm{sc}}\left(\frac{\mathrm{d} i_{c}}{\mathrm{~d} t}\right)
$$

As see above, Vce/sc(on) is the return of the saturation of the induction voltage value, Vbus is the bus voltage value, Lsc is the short-circuit circuit inductance value.

For the series-connected stakpak IGBTs, the change of Vce, Ic and Vge when short-circuit II fault is same with curve in Figure 2. As the device parameters cannot be completely consistent, the characteristics of short circuit II in series is shown as follows.

\subsection{The External Characteristic Difference Between Single and Series-Connected IGBTs of SC II}

When a short circuit fault occurs, the driver detects the fault signal and turn off the fault IGBT.

When short-circuit II fault occurs, each series-connected IGBTs driver detect the fault signal and issue shutdown instructions are unsynchronized as the device parameters cannot be completely consistent. Secondly, considering the dispersion of IGBT gate parasitic parameters, the IGBT gate actually received fault shutdown the signal time difference will be further increased, the bus voltage is much higher than that of single IGBT, the IGBT will bear all the bus voltage which first off, resulting in this IGBT overvoltage breakdown. In conclusion, when series-connected IGBTs short-circuit fault occurs, improve the speed of circuit detection, reduce the difference between the fault shutdown signal, and synchronization off as much as possible.

\subsection{The Turning-Off Voltage Characteristic Difference Between Single and Series-Connected IGBTs of SC II}

The di/dt of short-circuit fault is much higher than that of the normal shutdown, so the peak of Vce/sc is much higher when short circuit, then use the active clamp circuit (AVC) to suppress overvoltage peak.

For series-connected IGBTs in short circuit II, it must be voltage-balancing when short-circuit II fault. The voltage-balancing of series-connected IGBTs when short-circuit II fault divided into two aspects: 1) the voltage-balancing of the time of shut off, 2) the voltage-balancing of the time of tail current stage after shut off. Due to the dispersion nature of the parasitic parameters of the series-connected IGBTs and the un-synchronization of the time of the fault shutdown time cause the dynamic voltage-unbalancing of the series-connected IGBTs. Secondly, the voltage peak much higher than the normal situation when short-circuit II which is further deteriorate the dynamic voltage-unbalancing. In addition, when the gate voltage of 
Vge reduced to below the threshold voltage in the turning-off process, the collector current Ic take into the tail current stage, and the gate driver lost control of IGBT. Due to the dispersion nature of the parasitic parameters of the IGBTs, the current attenuation in the tail current stage can not be exactly the same even if same series valve, which causing voltage-unbalancing of the series-connected IGBTs in the tail current stage.

The rate of the voltage-unbalancing of the series-connected IGBTs [13] can be expressed as $\alpha=\left(\Delta V / V_{\mathrm{n}}\right) \times 100 \%$, which $V n$ is the average voltage of each series device, $\Delta V$ is the absolute value of the difference between the actual voltage and the average voltage.

\section{Protection Method for Short Circuit II for Series-Connected Stakpak IGBTs}

\subsection{Logic Scheme of Short Circuit in Series Fault Test}

At present, the conventional short circuit fault detection methods of IGBT include Vce back saturation detection and the di/dt detection of the small inductance which within the auxiliary E and power E [14]. For series-connected stakpak IGBTs, due to the special encapsulation of IGBT using double-sided cloth electrode package, module internal auxiliary e and E power are the same contact electrode and no small parasitic inductance between them, so cannot use $\mathrm{di} / \mathrm{dt}$ fault detection method. Secondly, short circuit II of the large power IGBT occurs in the turning-on process, the Vce voltage is greatly reduced, the Vce detection method is slow. Longer short circuit detection blind area can make the IGBT long time in short circuit operation mode, increase the risk of short circuit failure of IGBT [15]., so need to adjust the circuit parameters of Vce sampling, shorten the short detection zone time.

In two series-connected IGBTs as an example, the detection principle of series short circuit II fault is shown in Figure 3. Fault detection using diode network to detect Vce voltage. The theoretical basis is, Ic in the period of current flow through the valve each IGBT series is completely consistent, and before the Vce voltage of each IGBT returned to saturation, the collector current Ic is positively correlated with the collector emitter voltage Vce. When Ic exceeds the rated operating current to a certain extent, and the series-connected IGBTs showed no obvious desaturation occurs, it generates short circuit II fault in series. According to the Ic-Vce curve in the datasheet can get Vce under a short-circuit current, and set it is the reference voltage Vref. And then compare Vref with the collected voltage Vce of each IGBT. Set the action value of the detection loop is $4 \mathrm{kA}$, when Ic more than $4 \mathrm{kA}$, Vce $>$ Vref. The detection circuit outputs a fault signal to the driver.

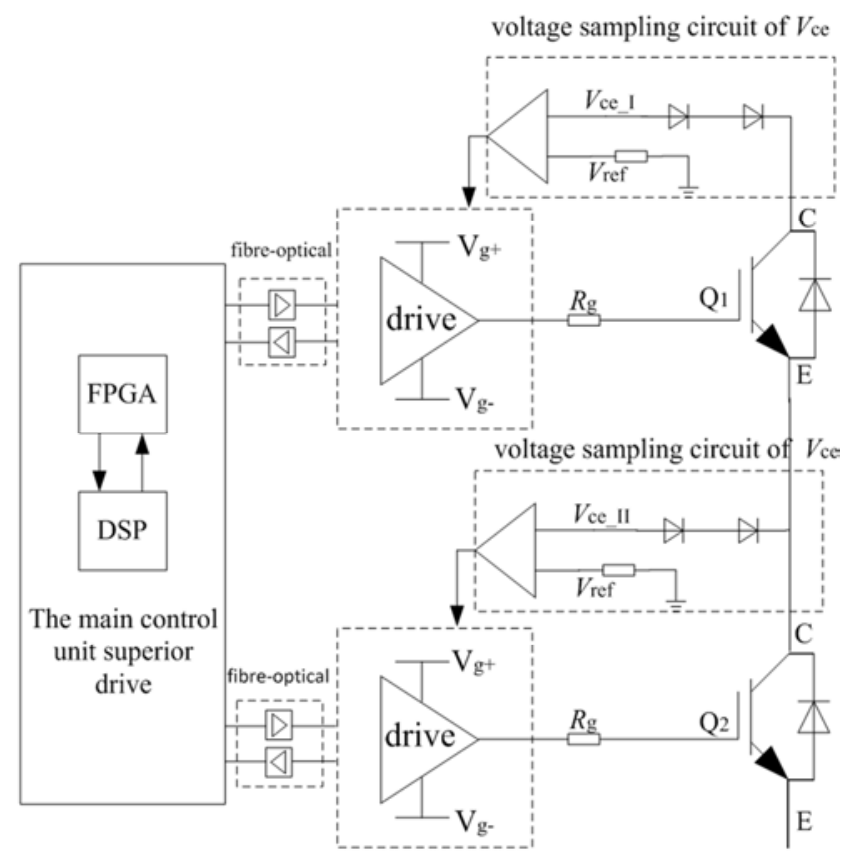

Figure 3. Vce voltage detection logic diagram of SC II for series IGBTs.

After the short circuit fault signal is received, the driver should be as close as possible to turn off the fault IGBT, so as to reduce voltage-unbalancing, then short circuit protection based on the logic of SC II fault processing used by the main control unit was proposed. The logic sequence diagram of SC II for series IGBTs is shown in Figure 4, high level representation to detect short circuit faults. Due to the difference of the parasitic parameters of IGBT itself, the driver of Q1 first detects the short circuit fault in t0 time, and converts the fault signal to the optical signal upload to drive the main control unit, and receives the fault signal and locks it. At the same time, all the IGBT (Q1 and Q2) in the series valve issue shutdown instructions, the driver will turn off the light signal into electrical signals and the implementation of the shutdown instructions.

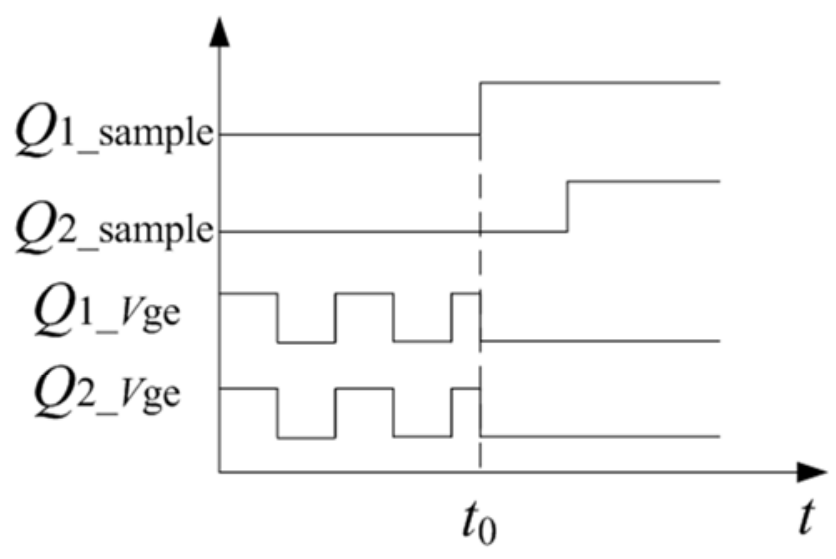

Figure 4. The logic sequence diagram of SC II for series IGBTs.

\subsection{Voltage-Balancing Method of Short Circuit in Series}

The short-circuit fault current in series-connected IGBTs facing a new voltage-unbalancing problem: similar with 
single IGBT in short circuit fault, using an active voltage clamping circuit to balance the dynamic voltage during breakdown, using an $\mathrm{RC}$ circuit to balance the voltage during tail current stage.

The basic AVC clamp circuit constituted by TVS, fast recovery diode and current limiting resistor, as shown in Figure 5: Rs1 and Rs2 are the current limiting resistors in active clamp circuit respectively, D1 and D2 are fast recovery diode respectively, $\mathrm{D}_{\mathrm{Z} 1}$ and $\mathrm{D}_{\mathrm{Z} 2}$ are TVS tubes of each IGBT.

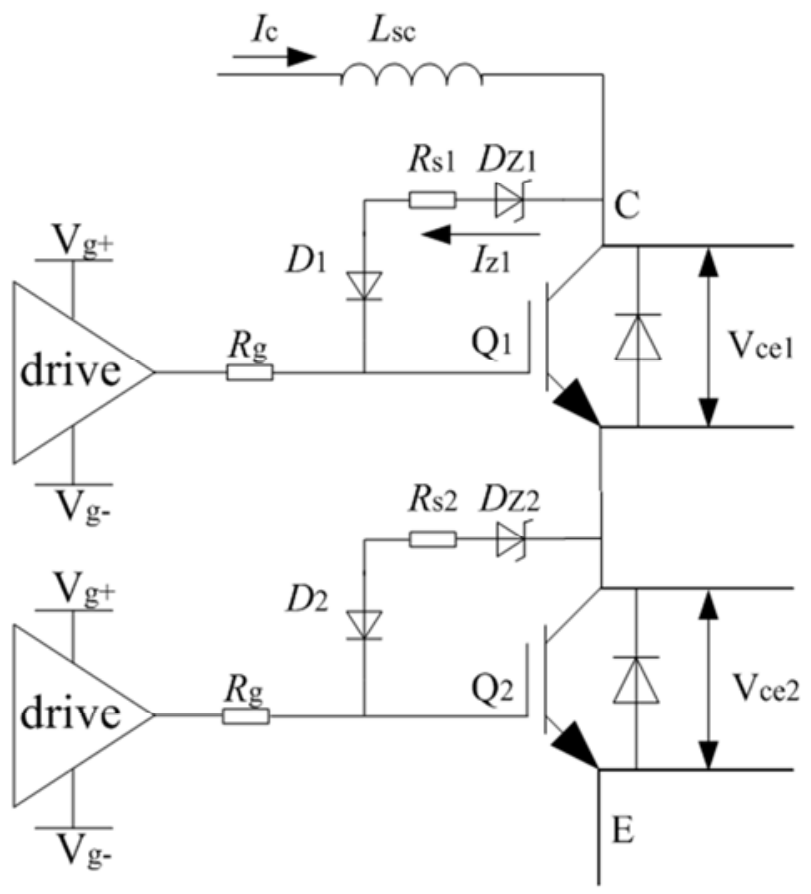

Figure 5. Diagram of AVC during SC II for series IGBTs.

When the voltage between the collector and emitter of the IGBT exceeds the reverse breakdown voltage of the TVS tube, then current flow through TVS, some charge from the collector to the gate in order to keep the gate voltage threshold voltage Vgeth. IGBT works in a linear mode, equivalent to a voltage controlled current source. Therefore, the over voltage on the IGBT is clamped in the reverse breakdown voltage level of the TVS tube, and then the energy stored on the stray inductance Lsc is consumed on the IGBT, taking the Q1 tube as an example, the clamping time of TVS is [6]:

$$
T_{\text {clamping }} \approx \frac{L_{\mathrm{sc}} \times I_{\mathrm{c}}}{V_{\mathrm{z} 1}-V_{\mathrm{cel}}}
$$

As see above: Lsc is the stray inductance, Ic is the clamped current, Vz1 is the clamp voltage of Q1 tube, Vce1 is the collector-emitter voltage of Q1 tube.

The power consumption of the clamp circuit is:

$$
P_{\text {sw_TVS }}=F_{\text {sw }} \times T_{\text {clamping }} \times I_{\mathrm{z}} \times V_{\mathrm{z} 1}
$$

In the formula, $\mathrm{P}_{\mathrm{sw} \text { TVS }}$ is the power consumption of the clamp circuit, Fsw is the clamp circuit's operating frequency, Iz is the current that flows through the TVS tube, the Vzl is the clamp action voltage.

In the series short circuit test, considering the clamp time and power consumption, the AVC circuit is composed by 7 TVS tube series, the reverse clamp voltage is 300 Vof each TVS tube, the power is $600 \mathrm{~W}$, the highest voltage clamp is $2100 \mathrm{~V}$.

The method is using an $\mathrm{RC}$ circuit to balance the voltage during tail current stage. In two series-connected IGBTs as an example, assumed that the series-connected IGBTs is voltage-unbalancing in the shutdown time. When series IGBTs entered the tail current stage in t0, and the current is I0. $\mathrm{I}_{\mathrm{C} 1}$ and $\mathrm{I}_{\mathrm{C} 2}$ is the tail current of this two series IGBTs, Vce1 and Vce2 are the collector-emitter voltage respectively, Vbus is DC bus voltage. That decline of the tail current decay is exponential function approximation, two series tail current time constant is $\tau_{1}$ and $\tau_{2}$ of series-connected IGBTs respectively. The voltage-balancing caused by the tail current all absorbed by the capacitor $\mathrm{C}$, ignoring the current limiting resistance Rs, $\Delta t$ time later, the relationship between voltage and current of the series-connected IGBTs is expressed as follows:

$$
\begin{aligned}
& C \times\left[V_{\text {cel }}\left(t_{0}+\Delta t\right)-V_{\text {cel }}\left(t_{0}\right)\right]= \\
& I_{0} \times\left(e^{-\frac{t_{0}}{\tau_{2}}}-e^{-\frac{t_{0}}{\tau_{1}}}\right) \times \Delta t+C \times\left[V_{\text {ce } 2}\left(t_{0}+\Delta t\right)-V_{\text {ce } 2}\left(t_{0}\right)\right]
\end{aligned}
$$

Simplify as:

$$
C \times V_{\text {cel }}^{\prime}=I_{0} \times\left(e^{-\frac{t_{0}}{\tau_{2}}}-e^{-\frac{t_{0}}{\tau_{1}}}\right)+C \times V_{\mathrm{ce} 2}^{\prime}
$$

and: $\quad V_{\text {cel }}+V_{\text {ce2 }}=V_{\text {bus }}$

The voltage difference of series IGBTs in tail current stage:

$$
\begin{aligned}
\Delta V & =V_{\mathrm{ce} 1}-V_{\mathrm{ce} 2} \\
& =\frac{I_{0}}{C} \times\left(\int e^{-\frac{t_{0}}{\tau_{2}}} \mathrm{~d} t-\int e^{-\frac{t_{0}}{\tau_{1}}} \mathrm{~d} t\right)
\end{aligned}
$$

After (4 5) $\tau$, consider the two series-connected IGBTs tail current reduced to zero, and the absorption capacitance expressions:

$$
C=\frac{I_{0}}{\Delta V} \times\left(\tau_{2}-\tau_{1}\right)
$$

According to 60747-9:2007 IEC: the duration of the tail current is $0.1 \mathrm{Ic} \sim 0.02 \mathrm{Ic}$. The rated current of the Stakpak IGBT is $2000 \mathrm{~A}$, take I0 $=125 \mathrm{~A}$, Difference of the tail current time constant of two series-connected IGBTs is $0.5 \mu \mathrm{s} \sim 1.0 \mu \mathrm{s}$, Vbus $=2000 \mathrm{~V}, \Delta V$ controlled within $5 \%$ Vbus, then can calculate $\mathrm{C}=0.5 \mu \mathrm{F}$ or $1 \mu \mathrm{F}$.

Considering the loss and other factors, take $\mathrm{R}=18 \Omega$.

\section{Experimental}

\subsection{Test Principle}

In this paper, the model of the IGBT used in the test is ABB 5SNA1400K 451300 , rated voltage is $4500 \mathrm{~V}$, rated current is 2000A. The SC II schematic of two series-connected IGBTs 
as shown in Figure 6, the parameters as shown in table 1:

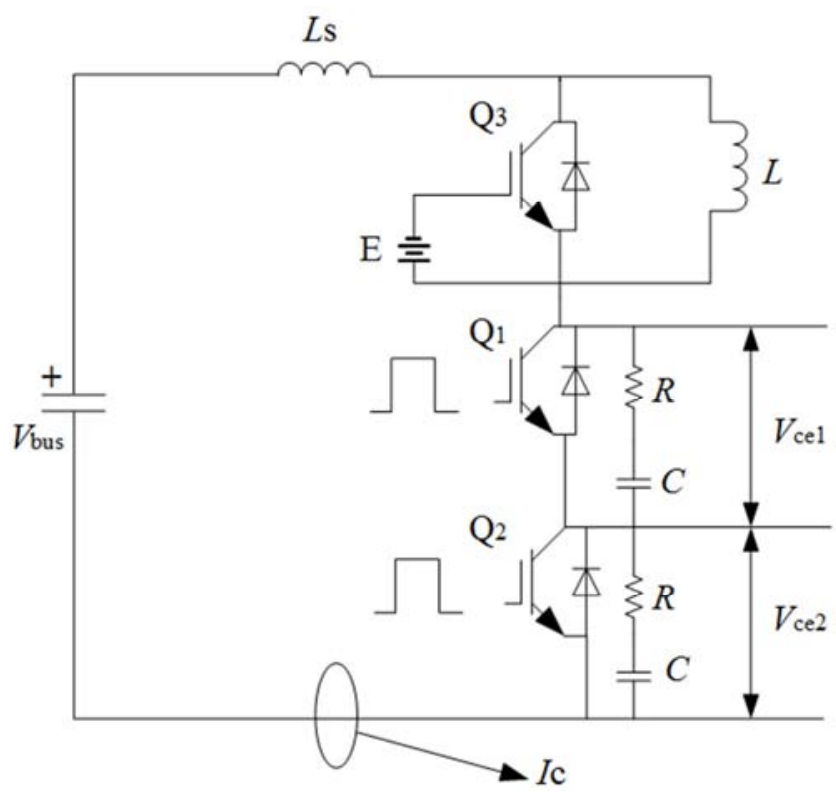

(a) schematic of the test platform

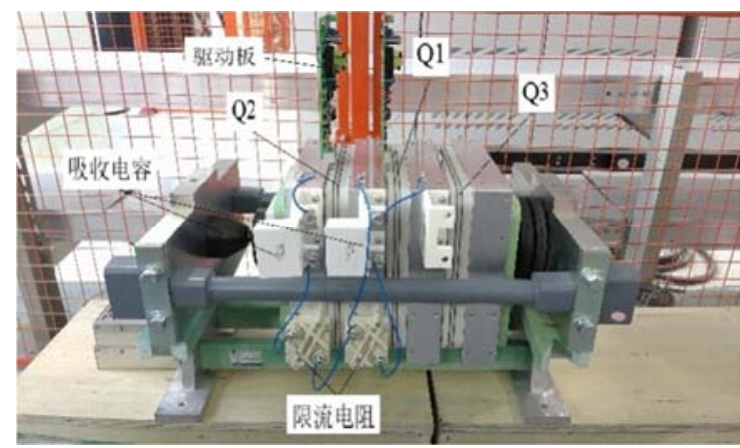

(b) module structure of two series-connected stakpak IGBTs

Figure 6. SC II schematic of two series-connected IGBTs.

Table 1. Parameters of the test platform.

\begin{tabular}{lll}
\hline variable & & value \\
\hline DC bus & Ubus & $1400 \mathrm{~V}$ \\
short circuit inductance & $\mathrm{L}$ & $1.5 \mu \mathrm{H}$ \\
AVC clamp voltage & - & $2100 \mathrm{~V}$ \\
voltage balancing capacitor & $\mathrm{C}$ & $0.56 \mu \mathrm{F}$ \\
current-limiting resistance & $\mathrm{RS}$ & $18 \Omega$ \\
\hline
\end{tabular}

\subsection{Test Result}

Set DC bus Vbus $=1400 \mathrm{~V}$, clamp voltage is $2100 \mathrm{~V}$, using the conventional fault protection scheme: Vce desaturation detection circuit. The driver of the series IGBTs process fault signal and shut down no dynamic absorption circuit respectively. Waveform of series SC II in traditional protection measurement is shown in Figure 7. Due to the

Dispersion characteristics of IGBT, the Q1 tube and Q2 tube appear to be un-synchronous, Q1 driver detect the SC fault signal and send shutdown instruction the command firstly, and voltage spike is clamped at $2100 \mathrm{~V}$, and Q1 bear all bus voltage $1400 \mathrm{~V}$. Q2 was not detected the fault signal and maintain the collector emitter saturation voltage.

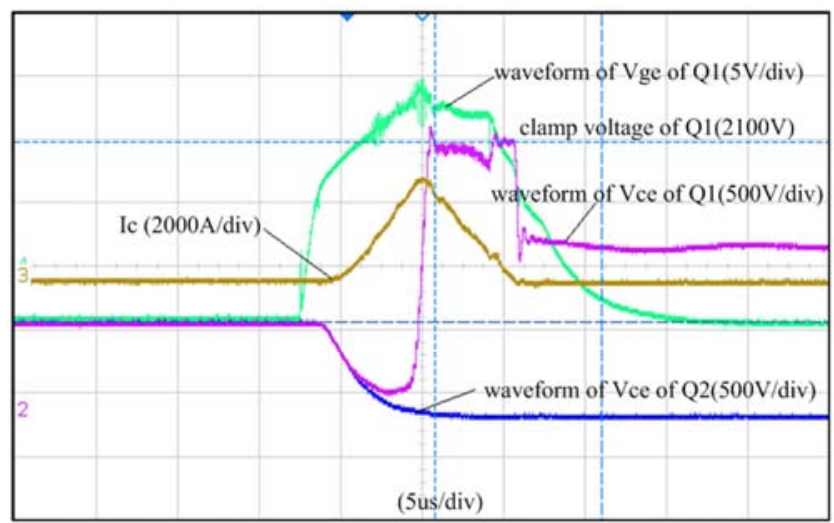

Figure 7. Waveform of series SC II in traditional protection measurement.

DC bus Vbus $=1400 \mathrm{~V}$, no active clamp circuit in series with a special fault protection scheme: setting the current operating point of the Vce voltage fault detection circuit is 4000A. The superior control unit output the fault shutdown signal and applying the RC absorption circuit. Waveform of series SC II in new protection measurement without AVC is shown in Figure 8. Due to the difference characteristics of Q1 and Q2 tube, they are un-synchronization in turning-off time, the peak turning-off voltage ofQ1 tube is 2650Vfirstly, the peak voltage of Q2 is $1760 \mathrm{~V}$, steady state voltage difference of them is $125 \mathrm{~V}$ when completely turning- off, and the voltage unbalance of steady stage voltage is $9.8 \%$.

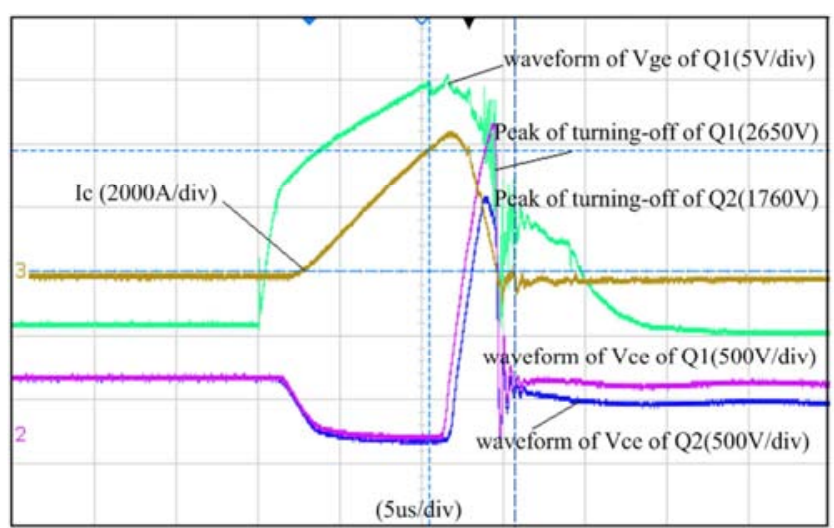

Figure 8. Waveform of series SC II in new protection measurement without $A V C$.

Comparison of Figures 7 and 8, after use of the scheme of the special fault protection logic in series, the steady-state voltage difference is decreased from $1400 \mathrm{~V}$ to $125 \mathrm{~V}$, the unbalance degree of steady state shutdown voltage is reduced from $100 \%$ to $9.8 \%$. It explain: the protection logic of all series IGBT synchronous actions can effectively improve the consistency of the protection action when the series IGBT short circuit faults are connected in series, but as the dynamic shutdown voltage spikes are not completely consistent, simply by parallel RC resistance capacitance loop can improve the voltage balancing, but cannot completely realize the voltage-balancing in fault.

DC bus Vbus $=1400 \mathrm{~V}$, clamp voltage is $2100 \mathrm{~V}$, waveform of series SC II in new protection method is shown in Figure 9. 
In the case of series turning-off is not synchronized, the peak of turning-off voltage of Q1 and Q2is clamped at $2100 \mathrm{~V}$, the steady-state off voltage difference is $45 \mathrm{~V}$, the voltage unbalance of steady stage voltage is $4 \%$.

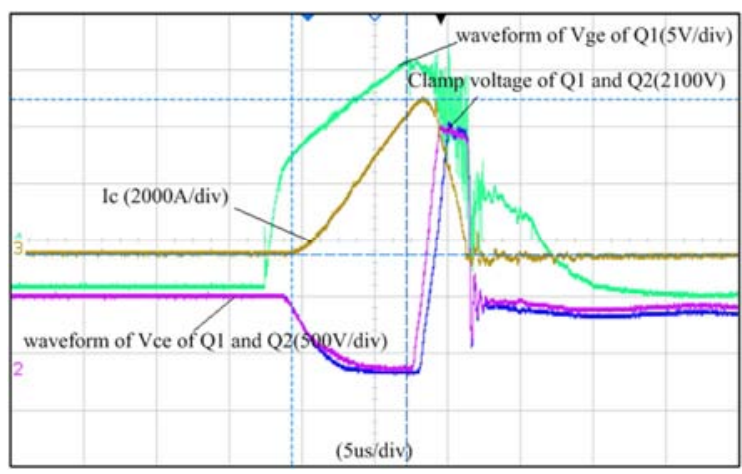

Figure 9. Waveform of series SC II in new protection method with AVC $2100 \mathrm{~V}$.

Comparison of Figures 8 and 9, series special protection fault logic is used in the two conditions. When the AVC clamp protection circuit is enabled, the fault voltage spike is reduced from the highest value $2650 \mathrm{~V}$ to $2100 \mathrm{~V}$, the steady-state voltage difference is reduced from $125 \mathrm{~V}$ to $45 \mathrm{~V}$, the unbalance degree of steady state shutdown voltage is reduced from $9.8 \%$ to $4 \%$, which can further reduce voltage-unbalancing in fault in series. Based on the experimental results above, combined with the superior master control unit, IGBT and clamping circuit, RC absorption circuit and other protective measures, can achieve the series short-circuit II fault in the whole process of the voltage-balancing.

\section{Conclusion}

According to the short circuit II fault of IGBT, as the stakpak IGBT as an example, this paper analysis the difference between single and series-connected IGBTs during short circuit II detailed. A new principle of short circuit protection based on the logic of SC II fault processing used by the main control unit was proposed, using an active voltage clamping circuit to balance the dynamic voltage during breakdown, using an $\mathrm{RC}$ circuit to balance the voltage during tail current stage, and a formula to estimate the absorption capacitance and the selection principle of static voltage balancing resistance was proposed. On the basis theory above, design the Vbus $=1400 \mathrm{~V}$ (the peak voltage of single IGBT is $2650 \mathrm{~V})$, Isc is $4000 \mathrm{~A}$. The result shows that the new protection method can provide the synchronization of protect operation and voltage balancing during turning-off process, and the unbalance of steady stage voltage is under $5 \%$.

\section{Acknowledgements}

This paper is one of the stage results of the prototype of the flexible HVDC converter valve based on localization IGBT in the National Science and Technology Major Project of China (2015ZX02301003).

\section{References}

[1] ZHANG Fan, YANG Xu, REN Yu, CHEN Ying, GOU Ruifeng. Voltage Balancing Circuit for Series-connected IGBTs in Solid-state Breaker [J]. Proceedings of the CSEE, 2016, 36(3): 656-663.

[2] ZHAOF Dong-yuan, LIU Jiang. Application Analysis of the Press-pack IGBT in the Power Electronic Field [J]. Power Electronics. 2015, 49(12): 46-48.

[3] Dou Zechun, Rupert Stevens, Xin Lanyuan, et al. Design and characteristic analysis of novel press-contact IGBT module [J]. Electric Drive for Locomtives, 2013, 1(01): 10-13.

[4] FENG LEI, GOU Ruifeng, ZHUO Fang. Development of 10 $\mathrm{kV}$ Solid State DC Breaker Based on IGBT Series-connected Technique [J]. SOUTHERN POWER SYSTEM TECHNOLOGY. 2016, 10(4): 43-49.

[5] Nakatake H, Iwata A. Series connection of IGBTs used multilevel clamp circuit and turn off timing adjustment circuit [C]. Proceedings of IEEE 34th Annual Power Electronics Specialist Conference, 2003, 4: 1910-1915.

[6] LUTing, Zhao Zhengming, JiShiqi, et al. Active clamping circuit with status feedback for series-connected HV-IGBTs [J] IEEE Transactions on Industry Applications, 2014, 50(5): 3579-3590.

[7] YU Hualong, LU Ting, JI Shiqi, YUAN Liqiang, ZHAO Zhengming. Active Clamping Circuit Threshold Voltage Design for Series-connected HVIGBTs [J]. Proceedings of the CSEE, 2016, 36(5): 1357-1365.

[8] Zhang Bingjing. Research on the unbalancing dynamic voltage of Serial Press-contact IGBT [D]. North China Electric Power University, 2014.03.

[9] Xingyu Li. The Research of Series Connected Diode Clamping IGBT Equalizing [D]. Beijing Institute of Technology, 2016. 01 .

[10] Liu Zhouzhou, Tong Xiangqian. Analysis of short circuit protection mechanism of high power IGBT device [J]. Electric drive, 2015, 45(3): 77-80.

[11] Yao Wenhai, Cheng Shanmei, Sun Dejin. Soft turn-off short circuit protection strategy applied to high power IGBT module [J]. Electric drive, 2015, 45(3): 77-80.

[12] Lutz J, Dobler R, Mari J, et al. Short circuit III in high power IGBTs [C]. Proceeding of the EPE 13th European conference, 2009: 1-8.

[13] PANG Hui, WEN Jialiang, HE Zhiyuan, et al. Unbalancing Voltage of High Power Series Connected IGBT Valve [J]. Proceeding of the CSEE, 2011, 31(21): 1-8.

[14] Yao Wenhai, Cheng Shanmei, Li Wujie, et al. Short-circuit strategy of IGBT based on di/dt and voltage combination detection [J]. Power Electronics, 2013, 47(12): 57-59.

[15] WEI Feng, LI Li. Short-circuit Features of High Voltage IGBT in di/dt Buffer Circuit [J]. The World of Power Supply, 2013, 06: 32-35. 